\title{
TRATADOS BILATERALES DE INVERSIÓN Y DERECHOS HUMANOS: TRES POSICIONES DESDE AMÉRICA LATINA
}

\author{
Lucas Sebastián de Erice Aranda* \\ Universidad de La Laguna
}

\section{RESUMEN}

Este artículo tiene como objeto analizar el modo en el cual la firma de nuevos tratados bilaterales de inversión puede llegar a convertirse en una limitación autoimpuesta por los Estados a su capacidad de cumplimiento de sus obligaciones en materia de derechos humanos. Para ello se analizarán las principales características de dichos acuerdos y los puntos de fricción más importantes con el Derecho Internacional de los Derechos Humanos. Así mismo, se estudiarán las posibles vías de acción que tienen a su disposición los Estados para tratar de resolver dicha tensión, a través del estudio de tres ejemplos latinoamericanos: México, Ecuador y Brasil.

Palabras Clave: tratados bilaterales de inversión, obligaciones en materia de derechos humanos, autolimitación.

\section{BILATERAL INVESTMENT TREATIES AND HUMAN RIGHTS: \\ THREE POSITIONS FROM LATIN AMERICA}

\section{Abstract}

The purpose of this article is to analyze the way in which the signing of new bilateral investment treaties can become a self-imposed limitation by the States to their ability to comply with their human rights obligations. Therefore, the main characteristics of these agreements will be analyzed, as well as the main points of collision with the International Human Rights Law. Likewise, the possible courses of action that the States have at their disposal to try to resolve that tension will be studied, through the example of three Latin American countries: Mexico, Ecuador and Brazil.

KEYwords: bilateral investment treaties, obligations on human rights, self-imposed limitation. 


\section{INTRODUCCIÓN}

Las últimas décadas de globalización han dibujado un panorama mundial basado en una economía interdependiente en la que los Estados, sujetos originarios del Derecho Internacional Público (DPI), comparten escenario con las grandes empresas transnacionales (ETN). Estas corporaciones tienen miles, incluso millones de trabajadores, sedes e inversiones repartidas por todo el globo y una gran capacidad económica, capaz de competir con muchos países. Las empresas buscan oportunidades de negocio en todo el planeta, y los Estados tratan de atraer inversión extranjera que pueda incentivar su desarrollo económico. Para fomentar y gestionar este intercambio, surge el régimen de protección de las inversiones (RPI), un sistema mediante el que los Estados receptores de inversión tratan de generar un escenario atractivo y de cierta estabilidad jurídica para el desarrollo de actividades empresariales. Un elemento clave de dicho régimen son los tratados bilaterales de inversión (TBI), acuerdos internacionales entre dos Estados para fomentar la inversión privada que, como todo convenio de DPI, genera una serie de obligaciones recíprocas.

Estos acuerdos tienen como objetivo principal promover la inversión extranjera $^{1}$, motor de gran importancia para la economía y el desarrollo de todos los Estados. Para ello, tratan de garantizar la seguridad jurídica de las inversiones a través de una serie de cláusulas que protejan los intereses de los inversores extranjeros. Una de las principales características de estos tratados es la inclusión de un sistema de resolución de controversias inversor-Estado (ISDS) ${ }^{2}$ que permite a las propias empresas denunciar a los Estados por el posible incumplimiento de algunas de sus cláusulas. En ocasiones ante los tribunales nacionales, pero por lo general ante tribunales internacionales de arbitraje.

El primer TBI se firmó entre la República Federal de Alemania y la República Islámica de Pakistán en el año 1959, y en los años sesenta y setenta se convirtió en práctica habitual entre los países exportadores de capital y, en mayor medida,

* Universidad Autónoma de Madrid, doble graduado en Derecho y Ciencias Políticas y de la Administración Pública. Universidad Politécnica de Valencia, máster en Cooperación Internacional al Desarrollo. Universidad Carlos III, experto en Pueblos Indígenas, Derechos Humanos y Cooperación Internacional. Universidad de La Laguna, doctorando en el Programa de Doctorado en Derecho, Sociedad y Turismo.

${ }_{1}$ Pese a lo anterior, diversos autores ponen en duda que haya una relación directa entre TBI y aumento de la inversión extranjera. Neumayer, E. y Spess, L., «Do Bilateral Investment Treaties Increase Foreign Direct Investment to Developing Countries?», World Development, núm. 1 (3), 2005, pp. 31-49. Incluso la Conferencia de Naciones Unidas sobre el Comercio y el Desarrollo (UNCTAD) ha reconocido en varios informes que, dependiendo del método de análisis que se utilice, los TBI parecen tener muy poco o ningún efecto en los flujos de inversión extranjera directa entre el Norte y el Sur. Como veremos más adelante, en este sentido destaca el caso de Brasil, que pese a no tener ningún TBI en vigor es el mayor receptor de inversiones de Latinoamérica.

${ }^{2}$ En referencia a las siglas en inglés de Investor-State Dispute Settlement. 
Estados africanos y asiáticos ${ }^{3}$, alcanzando la cifra de 386 acuerdos en el año $1989^{4}$. A partir del Consenso de Washington ${ }^{5}$ de la mano de las políticas económicas basadas en la liberalización del mercado, la privatización de los servicios y la apertura a la inversión extranjera, se firmaron cientos de TBI a los que se incorporaron gradualmente la mayoría de los países latinoamericanos ${ }^{6}$. Sólo en la década de los noventa se firmaron 1600 acuerdos $^{7}$. El ritmo de celebración de nuevos tratados se mantuvo en el tiempo y, según datos de la Conferencia de Naciones Unidas sobre Comercio y Desarrollo (UNCTAD), en la actualidad existen 3284 TBI en vigor ${ }^{8}$.

Este artículo expondrá de qué manera dichos acuerdos pueden suponer una clara limitación, consciente y voluntaria, de la capacidad de los Estados de cumplir con otra serie de importantes obligaciones: aquéllas generadas por el Derecho Internacional de los Derechos Humanos (DIDH). Con este objetivo, en primer lugar, se efectúa un análisis de las principales características de los TBI, y se exponen los principales puntos de colisión con las obligaciones en materia de derechos humanos. En segundo lugar se estudian las alternativas de acción estatal ante tal tensión. Para ello se pone especial atención en el ámbito latinoamericano, región de gran interés para la temática ya que en la actualidad concentra gran parte de los debates políticos, doctrinales y jurídicos alrededor del RPI. Las alternativas de acción

${ }^{3}$ Férnandez de Gurmendi, S., «Los Convenios Bilaterales de promoción y protección de inversiones extranjeras», Relaciones Internacionales, núm. 1 (3), 1992. Disponible en https://revistas.unlp.edu.ar/RRII-IRI/article/view/2008.

${ }^{4}$ VANDEVelde, Kenneth J., "A Brief History of International Investment Agreements», UC Davis Journal of International Law \& Policy, vol. 12, núm. 1, 2005, pp. 157-194. Disponible en http://ssrn.com/abstract=1478757.

${ }^{5}$ Concepto acuñado por el economista británico John Williamson para definir el paquete de medidas de estabilización y ajuste económico acordadas por instituciones como el Fondo Monetario Internacional, el Banco Mundial y la Reserva Federal de Estados Unidos a finales de los ochenta. Entre las medidas destacaban la lucha contra el déficit público, las reformas para reducir los impuestos y desregular los mercados laborales, la privatización de servicios públicos o el fomento de la inversión extranjera directa (IED). Martínez Rangel, R. y Reyes Garmendia, E., «El Consenso de Washington: la instauración de las políticas neoliberales en América Latina», Politica Cultural, núm. 37, 2012, pp. 35-64. Disponible en http://www.scielo.org.mx/scielo.php?pid=S0188-77422012000100003\&script=sci_abstract.

${ }^{6}$ Esta demora en la incorporación de los países latinoamericanos se explica por el arraigo de las doctrinas Calvo y Drago en la región. Ambas defendían que los inversores extranjeros deben recibir el mismo trato que los inversores nacionales, por lo que no es necesario someterse a un arbitraje internacional. BeLLo, F., «La responsabilidad internacional del Estado. Las Doctrinas Calvo y Drago", Revista de Ciencias Jurídicas, núm. 16, 1970, p. 8. Disponible en https://revistas.ucr.ac.cr/ index.php/juridicas/article/view/16742/16236.

7 TRAIDCRAFT, Los acuerdos internacionales de inversión a examen. Traidcraft, 2015. Disponible en https://www.ecologistasenaccion.org/wp-content/uploads/adjuntos-spip/pdf/examen-acuerdos-internacionales-inversion.pdf.

${ }^{8}$ Según el World Investment Report publicado el 16 de junio de 2020. UNCTAD, World Investment Report 2020: International Production beyond the Pandemic. United Nations Conference on Trade and Development, 16 de junio de 2020. Disponible en https:/unctad.org/system/ files/official-document/wir2020_en.pdf. 
estatal se ilustran con tres ejemplos de posturas muy diferenciadas y significativas: I) México y su opción continuista, fiel al sistema tradicional de protección de inversiones; II) Ecuador y su decisión de impugnar el sistema, denunciando y abandonado todos sus TBI; y III) el especial caso brasileño, Estado que nunca ha firmado un TBI y que en la actualidad ofrece un mecanismo alternativo de gran interés.

\section{LOS TBI DE VIEJA Y NUEVA GENERACIÓN}

A partir de la década de 2010, muchos acuerdos firmados en los años noventa alcanzaron su fecha de finalización ${ }^{9}$ o el momento en el que podían ser abandonados unilateralmente por una de las partes. Esto dio lugar a un fenómeno hasta el momento inédito, ya que se comenzaron a negociar nuevas versiones de los tratados. Los Estados tenían la opción de replantearse su política al respecto y hacer las cosas de forma distinta, incluyendo disposiciones más adaptadas a las necesidades actuales, o incluso tomar la decisión de no firmar nuevos acuerdos de inversión. Consciente de la importancia del momento, también Naciones Unidas comenzó a señalar la necesidad de repensar los nuevos acuerdos de inversión, señalando que debían buscar la coherencia con las nuevas políticas mundiales ${ }^{10}$. Los intereses y prioridades políticas no eran los mismos que en la década de los noventa y por ello la UNCTAD, de la mano del nuevo marco aportado por los Objetivos de Desarrollo Sostenible, comenzó a diseñar una estrategia de renovación de los TBI y a destacar la necesidad de una nueva generación de acuerdos. Sus argumentos principales fueron I) la necesidad de que la inversión sea parte central de las estrategias de desarrollo sostenible, II) el deseo de conseguir el desarrollo sostenible a través de inversiones más responsables y III) la certeza de que los tratados de vieja generación no servían para lograr estos objetivos. La UNCTAD señaló que los acuerdos firmados principalmente en los años noventa constriñen de forma excesiva la capacidad nacional de legislar a favor del desarrollo sostenible y se enfocan de manera exclusiva en proteger a los inversores sin hacer lo suficiente para promover la inversión para el desarrollo $^{11}$. De esta forma, la UNCTAD define un dicotomía clara entre el antiguo modelo de TBI, cuyo único objetivo era proteger las inversiones, y el nuevo: proteger las inversiones pero de forma coherente con el resto de políticas públicas. En este sentido se entiende como nueva generación de TBI aquellos acuerdos que incorpo-

${ }^{9}$ Los TBI tienen plazos variables, que suelen oscilar entre 10 y 25 años. La página oficial de la UNCTAD cuenta con un buscador de todos los TBI firmados a lo largo de la historia. https:// investmentpolicy.unctad.org/international-investment-agreements.

${ }^{10}$ UNCTAD, Trade and Development Report 2010: Employment, globalization and development, United Nations Conference on Trade and Development, 2010. https://unctad.org/es/system/files/official-document/wir2010_en.pdf.

${ }^{11}$ UNCTAD, Investment Policy Framework for Sustainable Development, United Nations Conference on Trade and Development, p. 19, 2015. https://unctad.org/en/PublicationsLibrary/ diaepcb2015d5_en.pdf. 
ran algunas de las recomendaciones de la UNCTAD frente a la vieja generación de acuerdos, tanto concluidos como en vigor, que no las incorporan.

En este artículo pond remos especial atención en la vieja generación, ya que, aparte de ser la más numerosa ${ }^{12}$, es sin duda la que genera mayor conflictividad respecto al tema que nos ocupa. En palabras de la UNCTAD:

Los tratados de primera generación «muerden». Casi todos los casos actuales conocidos de solución de controversias entre inversores y Estados se basan en tratados celebrados antes de 2010, que en su mayor parte contienen formulaciones generales y vagas [...]. Los tratados de primera generación perpetúan incoherencias. El hecho de que sigan existiendo provoca superposiciones y fragmentación en las relaciones entre tratados, así como problemas de interacción ${ }^{13}$.

\section{TBI Y DERECHOS HUMANOS}

Podríamos definir tres conflictos principales entre los $\mathrm{TBI}^{14}$ y el DIDH: I) la vocación de estabilidad del primero frente al ímpetu transformador del segundo, II) la intersección entre intereses empresariales y derechos humanos y III) la forma en la que los TBI suponen una limitación a la capacidad legislativa de los Estados, en especial en materia de derechos humanos.

\subsection{TBI y DIDH: UN DEBATE CONCEPTUAL}

La colisión fundamental entre el RPI de vieja generación y el DIDH es conceptual, y existe desde la propia razón de ser de ambos sistemas. Los TBI buscan seguridad jurídica, que en el ámbito de las inversiones suele significar previsibilidad: tener información que permita saber qué va a suceder. Por ello, los TBI buscan mantener, dentro de lo posible, el statu quo existente en el momento en el que el inversor tomó la decisión de invertir. Para ello, las cláusulas de los acuerdos buscan restringir en la medida de lo posible la capacidad estatal de reforma legislativa en materias que puedan afectar a los inversores. Intereses que, como veremos más adelante, se relacionan de forma muy estrecha con los derechos humanos.

En cambio, el DIDH busca, por definición, cambiar el statu quo. Los derechos humanos se plantean como objetivos a lograr y no como metas ya alcanzadas y para ello es necesario fomentar cambios. Los Estados tienen la obligación inter-

${ }^{12}$ La UNCTAD calcula que tan sólo el 5\% de los TBI puede considerarse de nueva generación.

13 UNCTAD, Reforma del régimen de acuerdos internacionales de inversión: fase 2, United Nations Conference on Trade and Development, 2017, p. 3. Disponible en https://unctad.org/ system/files/official-document/ciimem4d14_es.pdf.

${ }^{14}$ A partir de este punto, a no ser que se especifique lo contrario, nos referimos a TBI de vieja generación. 
nacional, consagrada en numerosos documentos, de adoptar las medidas oportunas para dictar las disposiciones legislativas, ejecutivas y judiciales que fueran necesarias para hacer efectivos los derechos humanos ${ }^{15}$. En este sentido la Convención Americana sobre Derechos Humanos establece el deber de adoptar disposiciones de derecho interno:

Si en el ejercicio de los derechos y libertades mencionados en el artículo 1 no estuviere ya garantizado por disposiciones legislativas o de otro carácter, los Estados partes se comprometen a adoptar, con arreglo a sus procedimientos constitucionales y a las disposiciones de esta Convención, las medidas legislativas o de otro carácter que fueren necesarias para hacer efectivos tales derechos y libertades ${ }^{16}$.

De la misma forma, la Corte Interamericana de Derechos Humanos ha señalado que

la obligación estatal de adecuar la legislación interna a las disposiciones convencionales no se limita al texto constitucional o legislativo, sino que debe irradiar a todas las disposiciones jurídicas de carácter reglamentario y traducirse en la efectiva aplicación práctica de los estándares de protección de los derechos humanos ${ }^{17}$.

Las vocaciones contrapuestas de ambos sistemas, la disputa entre estabilidad y transformación, colocan al Estado, tal y como señalan Bohoslavsky y Justo ${ }^{18}$, en el dilema de incumplir sus responsabilidades internacionales en materia de derechos humanos, o cumplirlas corriendo el riesgo de infringir acuerdos de inversión.

\subsection{INTERESES DEL INVERSOR Y DERECHOS HUMANOS}

Como ya se ha expuesto, el Estado tiene una obligación internacional clara de tomar medidas en materia de derechos humanos y los TBI establecen una serie de disposiciones que tratan de limitar la capacidad del Estado de modificar las disposiciones legales que afecten a los intereses del inversor. Siguiendo este razonamiento, si los intereses del inversor están relacionados con los derechos humanos el Estado podrá estar en riesgo de incumplir sus obligaciones internacionales. La segunda gran tensión entre los dos sistemas aquí analizados surge porque no cabe duda de dicha relación: existe un riesgo claro de colisión entre los intereses empresariales y los derechos humanos.

${ }^{15}$ Artículo 2 del Pacto Internacional de Derechos Civiles y Políticos.

16 Artículo 2 de la Convención Americana

17 Corte IDH. Opinión Consultiva OC-21/14 de 19 de agosto de 2014. Serie A N. 21. párr. 65. Disponible en https://www.corteidh.or.cr/docs/opiniones/seriea_21_esp.pdf.

${ }_{18}$ Bohoslavsky, J.P. y Justo, J.B., «Inversiones Extranjeras y Derechos Humanos: entre la permanencia y el cambio», Revista de la Secretaría del Tribunal Permanente de Revisión, núm. 5 (3), 2015, pp. 65-94. Disponible en https://dialnet.unirioja.es/servlet/articulo?codigo=5830174. 
En este sentido cabe destacar el extenso trabajo llevado a cabo por la Comisión Interamericana de Derechos Humanos (CIDH), que ha destacado en varios documentos los principales puntos de fricción potenciales entre proyectos empresariales y derechos humanos. La CIDH ha señalado el claro riesgo existente en el caso de los actores empresariales que brindan servicios públicos esenciales para la garantía de los derechos humanos como la salud, la educación, agua potable, electricidad o seguridad social ${ }^{19}$. También ha destacado cómo puede afectar a los derechos humanos a través de la afectación del medio ambiente, la acción de empresas con proyectos de extracción o explotación de materias primas ${ }^{20}$. Así mismo, también ha hecho referencia a los derechos laborales ${ }^{21} \mathrm{o}$ a los posibles conflictos con los intereses de las empresas de seguridad privada ${ }^{22}$. En lo que respecta a la posible colisión entre proyectos extractivos y los derechos de los pueblos indígenas y las comunidades afrodescendiente, la CIDH ha afirmado que

los megaproyectos de infraestructura o desarrollo, tales como carreteras, canales, represas, puertos o afines, así como las concesiones para la exploración o explotación de recursos naturales en territorios ancestrales, pueden afectar a las poblaciones indígenas con consecuencias particularmente graves, ya que ponen en peligro sus territorios y los ecosistemas que allí se encuentran, por lo cual representan un peligro mortal para su supervivencia en tanto pueblos, especialmente en los casos en que la fragilidad ecológica de sus territorios coincide con su debilidad demográfica ${ }^{23}$.

Precisado lo anterior, podemos afirmar que los intereses de las ETN y los derechos humanos están estrechamente relacionados. Por ello, si el Estado, cumpliendo su ya argumentada obligación internacional, toma nuevas medidas en materia de derechos humanos, éstas pueden afectar negativamente a los intereses de los inversores. Siguiendo con dicho razonamiento, si los TBI limitan la capacidad regulatoria del Estado en materias relacionadas con los intereses de los inversores, directamente limitan la capacidad estatal de legislar en materia de derechos humanos.

${ }^{19}$ CIDH/REDESCA/INF.1/19. Comisión Interamericana de Derechos Humanos, Empresas y Derechos Humanos: Estándares Interamericanos, Organización de Estados Americanos, 2019, párrafo 115. Disponible en http://www.oas.org/es/cidh/informes/pdfs/EmpresasDDHH.pdf.

${ }^{20} \mathrm{CIDH}, 2019$, op. cit., párrafo 100.

${ }^{21}$ CIDH, 2019, op. cit., párrafo 99.

22 OEA/Ser.L/V/II, CIDH, Informe sobre Derechos Humanos y Seguridad Ciudadana, Organización de los Estados Americanos, párrafo 73, 2009. Disponible en https://www.cidh.oas. org/pdf\%20files/SEGURIDAD\%20CIUDADANA\%202009\%20ESP.pdf.

${ }^{23}$ OEA/Ser.L/V/II, CIDH, Pueblos indígenas, comunidades afrodescendientes y recursos naturales: protección de derechos humanos en el contexto de actividades de extracción, explotación y desarrollo, Organización de los Estados Americanos, párrafo 247, 2015. 


\subsection{TBI COMO LIMITACIÓN A LA CAPACIDAD REGULATORIA EN MATERIA DE DERE- CHOS HUMANOS}

La tensión entre TBI y capacidad regulatoria en materia de derechos humanos es ampliamente reconocida por Naciones Unidas. La UNCTAD ha señalado en diversas ocasiones la necesidad de salvaguardar el derecho de los Estados de tomar medidas legislativas a favor del interés público y de asegurar que los límites que imponen los TBI a la soberanía estatal no constrińan de forma excesiva su capacidad regulatoria ${ }^{24}$.

Los principios rectores sobre las empresas y los derechos humanos de Naciones Unidas también hacen referencia explícita a dicha tensión, señalando:

Los acuerdos económicos concluidos por los Estados, ya sea con otros Estados o con empresas -tales como tratados bilaterales de inversión, acuerdos de libre comercio o contratos de proyectos de inversión- les brindan oportunidades económicas. Pero también pueden afectar al marco normativo nacional de los gobiernos. Por ejemplo, los términos estipulados en acuerdos internacionales de inversión pueden restringir la capacidad de los Estados para aplicar plenamente nuevas leyes en materia de derechos humanos, o exponerlos, en caso contrario, al riesgo de arbitrajes internacionales vinculantes. Por lo tanto, los Estados deben asegurarse de que retienen las facultades normativas y regulatorias para proteger los derechos humanos en el marco de tales acuerdos, sin dejar de ofrecer la necesaria protección a los inversores ${ }^{25}$.

Del mismo modo, dicha fricción está siendo un aspecto a tener en cuenta en las negociaciones del proyecto de Tratado Vinculante sobre empresas y derechos humanos ${ }^{26}$. El segundo borrador revisado del texto ${ }^{27}$ alude a los TBI, declarando que los ya existentes deberán ser siempre interpretados e implementados de forma que no se vea socavada la capacidad estatal de cumplir con las obligaciones estipuladas en las convenciones e instrumentos de derechos humanos. También añade que

${ }^{24}$ UNCTAD, Trade and Development Report 2015: Reforming International Investment Governance, United Nations Conference on Trade and Development, p. XI, 2015. https:/unctad. org/system/files/official-document/wir2015_en.pdf.

${ }^{25}$ ONU, Principios Rectores sobre las empresas y los Derechos Humanos: Puesta en práctica del marco de las Naciones Unidas para «proteger, respetar y remediar», Organización de las Naciones Unidas, 2001, p. 13. Disponible en https://www.ohchr.org/documents/publications/guidingprinciplesbusinesshr_sp.pdf.

${ }^{26}$ El Consejo de Derechos Humanos de Naciones Unidas aprobó el 26 de junio de 2014 la Resolución 26/9, a través de la cual decide establecer un grupo de trabajo intergubernamental de composición abierta sobre las empresas transnacionales y otras empresas con respecto a los derechos humanos, cuyo mandato será elaborar un instrumento jurídicamente vinculante para regular las actividades de las empresas transnacionales y otras empresas en el derecho internacional de los derechos humanos. Resolución disponible en https://ap.ohchr.org/documents/dpage_e.aspx?si=A/HRC/RES/26/9.

${ }_{27}$ Con fecha de 6 de agosto de 2020. Disponible en https://www.ohchr.org/Documents/ HRBodies/HRCouncil/WGTransCorp/Session6/OEIGWG_Chair-Rapporteur_second_revised_ draft_LBI_on_TNCs_and_OBEs_with_respect_to_Human_Rights.pdf. 
todo nuevo tratado o acuerdo de inversión pactado por las partes debe ser compatible con dichas obligaciones ${ }^{28}$.

La preocupación de Naciones Unidas sobre el riesgo de que los TBI limiten la capacidad estatal de tomar medidas en materia de derechos humanos es clara. A continuación se analizan los aspectos de estos acuerdos que presentan un mayor riesgo.

\section{LOS TBI DE VIEJA GENERACIÓN: PUNTOS DE FRICCIÓN CON LA CAPACIDAD REGULATORIA DE LOS ESTADOS CON ESPECIAL REPERCUSIÓN EN MATERIA DE DERECHOS HUMANOS}

Estos acuerdos suelen incluir un apartado centrado en enumerar los derechos de los inversores y una parte más procedimental, en la que se estipulan los correspondientes mecanismos a utilizar, incluido el sistema de solución de controversias. Destacan por no incluir posibles obligaciones de los inversores respecto a los derechos humanos. Ningún TBI de vieja generación menciona a estos últimos, con la excepción del modelo noruego, que los incluye en su preámbulo ${ }^{29}$.

La mayoría de los tratados incluyen cláusulas similares o idénticas, ya que la mayoría de los Estados utilizan modelos o borradores de acuerdo que se modifican levemente según las negociaciones con cada contraparte. Las disposiciones destacan por ser vagas y poco concisas, circunstancia que, como veremos posteriormente, ha demostrado ser muy problemática, debido al amplio margen de interpretación que suscitan. En palabras de la UNCTAD:

Broad and vague formulations of IIA ${ }^{30}$ provisions have enabled investors to challenge core domestic policy decisions -for instance, in environmental, financial, energy and health policies. They have also generated unanticipated, and at times inconsistent, arbitral interpretations of core IIA obligations, resulting in a lack of predictability as to the kinds of State measures that might violate a specific IIA provision $^{31}$.

Son muchas las cláusulas propias de los TBI que podrían ser estudiadas, pero por motivos de espacio no centramos en tres: I) nación más favorecida, II) trato justo y equitativo y III) prohibición de la expropiación. Así mismo, se exponen las

${ }^{28}$ Artículo 14.5 del Segundo Borrador Revisado.

${ }^{29}$ JАСОВ, M., «International Investment Agreements and Human Rights», Institute for Development and Peace, Universität Duisburg Essen, 2010. Disponible en http://www.humanrights-business.org/international_investment_agreements_and_human_rights.pdf.

${ }^{30}$ International Investment Agreements.

31 UNCTAD, UNCTAD's Reform Package for the international Investment Regime, United Nations Conference on Trade and Development, 2018, p. 16. Disponible en https://investmentpolicy.unctad.org/publications/1190/unctad-s-reform-package-for-the-international-investment-regime-2018-edition-. 
características de los mecanismos encargados de interpretar dichas cláusulas: los tribunales internacionales de arbitraje.

\subsection{La Cláusula de Nación Más Favorecida (CNMF)}

La CNMF es uno de los elementos más cruciales del sistema de protección de inversiones. El DPI la ha utilizado tradicionalmente para definir la situación en la que el Estado concedente contrae la obligación, con respecto a otro Estado, de tratar a éste en condiciones que no sean peores al trato que ha estado otorgando u otorgará al tercer Estado más favorecido, en virtud de un tratado independiente o por alguna otra causa ${ }^{32}$. Pese a lo anterior, ante instancias arbitrales, los inversores extranjeros no suelen alegar discriminación argumentando que el Estado receptor haya aplicado medidas más favorables a inversores de terceros Estados. En cambio, suelen invocar la CNMF para tratar de acceder a condiciones de TBI entre el Estado receptor y terceros Estados que incluyan formulaciones más favorables que el acuerdo que regula su relación ${ }^{33}$. Está interpretación se dio en primer lugar en el caso Mafezzini vs. Espańa, en el que el tribunal aceptó la petición de un demandante argentino que, en base a la cláusula de CNMF del TBI Argentina-España, argumentaba que se le debía aplicar un arreglo más favorable contenido en el TBI Chile-España ${ }^{34}$. Al aceptar esta interpretación, los árbitros internacionales han desvirtuado los TBI originales, ya que han permitido a los inversores ir «eligiendo» las cláusulas que les favorezcan más de los diferentes tratados ratificados por el Estado receptor de la inversión ${ }^{35}$.

Esta cláusula no supone una limitación de la capacidad regulatoria por sí misma, pero eso no significa que no entrañe riesgos, ya que puede provocar que la aplicación de un TBI por parte de los tribunales de arbitraje diste mucho de lo buscado por los Estados parte. Esto puede suponer un problema especialmente delicado si tenemos en cuenta los actuales esfuerzos de muchos países por modificar su política de protección de las inversiones, ya que de incluir la disposición CNMF, los nuevos tratados podrían ser interpretados aludiendo a convenios de «vieja generación»"

32 Definición del Relator Especial Sr. Endre Ustor, en el Documento A/CN.4/L.127/ de la Comisión de Derecho Internacional de Naciones Unidas, 1968.

33 Bas Vilizzio, M. y Michelini, F., «Arbitraje de inversiones y derechos humanos: un análisis particular del caso Philip Morris contra Uruguay», Comisión Sectorial de Investigación Cientifica, Universidad de la República de Uruguay, 2019, p. 26. Disponible en https://www.csic.edu.uy/ sites/csic/files/Bas\%20Vilizzio_Arbitraje\%20de\%20inversiones\%20y\%20derecho\%20humanos $\% 20$ Un\%20an\%C3\%A1lisis\%20particular\%20del\%20caso\%20Philip\%20Morris\%20contra\%20Uruguay_FDER.pdf.

${ }^{34}$ Caso Ciadi N. ${ }^{\circ}$ ARB/97/7, p. 9.

35 UNCTAD, 2018, op. cit., p. 33.

36 UNCTAD, 2018, op. cit., p. 34. 


\subsection{Trato Justo y Equitativo (TJE)}

Otra cláusula con gran arraigo histórico en los tratados internacionales, el TJE fue originalmente concebido como una medida de garantizar un trato mínimo a los extranjeros ${ }^{37}$. Obliga a los Estados a ofrecer a los nacionales de otros países garantías mínimas contra la denegación de justicia, la arbitrariedad y la discriminación ${ }^{38}$. De nuevo desvirtuando en cierta medida el sentido original, se ha convertido en una disposición que los inversores utilizan para denunciar cualquier tipo de conducta estatal que consideren injusta respecto a sus intereses ${ }^{39}$. Así mismo, la vaguedad en la que normalmente se plantea ha dado mucho margen de interpretación a los tribunales de arbitraje ${ }^{40}$.

Uno de los principales retos que han surgido a partir de diversos laudos es la interpretación de que la cláusula TJE protege las «expectativas legítimas» del inversor. La amplitud de este concepto genera un riesgo para los Estados, ya que pueden ver constreñida su capacidad regulatoria y de generación de nuevas políticas en materias relacionadas con las inversiones. En referencia al TJE, el Tribunal de Arbitraje CIADI en el caso TECMED vs. México señaló:

El Tribunal Arbitral considera que esta disposición [...] exige de las Partes Contratantes del Acuerdo brindar un tratamiento a la inversión extranjera que no desvirtúe las expectativas básicas en razón de las cuales el inversor extranjero decidió realizar su inversión. Como parte de tales expectativas, aquél cuenta con que el Estado receptor de la inversión se conducirá de manera coherente, desprovista de ambigüedades y transparente en sus relaciones con el inversor extranjero, de manera que éste pueda conocer de manera anticipada, para planificar sus actividades y ajustar su conducta, no sólo las normas o reglamentaciones que regirán tales actividades, sino también las políticas perseguidas por tal normativa y las prácticas o directivas administrativas que les son relevantes ${ }^{41}$.

Siguiendo esta argumentación, el Estado puede llegar a ver reducida de forma muy amplia su capacidad de adoptar medidas legislativas en todo lo relevante a los intereses del inversor, que como ya se expuso se relacionan de forma directa con los derechos humanos. Los riesgos de este tipo de disposiciones son tales que la UNCTAD señala la necesidad de modificar los contenidos de las cláusulas TJE, asegu-

37 Dupuy, P.M. y Viñuales, J.E., «Human Rights and Investment Disciplines: Integration in Progress", International Investment Law, Baden Baden: Nomos, 2012, p. 8. Disponible en https://papers.ssrn.com/sol3/papers.cfm?abstract_id=2125205.

${ }^{38}$ Bohoslavsky, J.P. y Justo, J.B., op. cit., p. 77.

39 ЈАСОВ, M., op. cit., p. 44.

40 A modo de ejemplo, el modelo de TBI de España incluye la siguiente redacción: «Cada Parte Contratante otorgará a las inversiones de inversores de la otra Parte Contratante, trato acorde con el derecho internacional consuetudinario, incluido trato justo y equitativo, así como protección y seguridad plenas».

${ }^{41}$ Caso Ciadi N. ${ }^{\circ}$ ARB (AF)/00/2, párrafo 154. Disponible en http://icsidfiles.worldbank. org/icsid/ICSIDBLOBS/OnlineAwards/C3785/DC4872_Sp.pdf. 
rando que en todo caso se preserve la capacidad de los Estados de adaptar políticas según cambien sus objetivos ${ }^{42}$.

\subsection{Cláusula de expropiación}

Hablamos de expropiación directa cuando la inversión es nacionalizada o de otra forma hay una transferencia del título de propiedad o se incautan físicamente los activos. La indirecta, cuando sin alteración de la titularidad «se produce una interferencia estatal significativa en el uso de dicha propiedad o el disfrute de sus beneficios» ${ }^{43}$. Los TBI sólo permiten la expropiación realizada por causas de utilidad pública conforme a las disposiciones legales, en ningún caso de forma discriminatoria, y siempre debe existir una indemnización.

Los inversores han aprovechado la difusa definición de expropiación indirecta para desafiar medidas legislativas que han podido tener un efecto negativo en sus intereses ${ }^{44}$. El principal problema llega a la hora de definir la frontera entre políticas públicas legítimas (restricciones en materia de medioambiente, medidas de salud pública, etc.) y expropiaciones que deben ser compensadas económicamente. De no definirse de manera clara, pueden surgir situaciones en la que los Estados deban indemnizar a las ETN por tomar medidas legislativas legítimas.

En este sentido destaca el famoso caso del CIADI Piero Foresti, Laura de Carli y otros vs. Sudáfrica. En el año 2004, el Gobierno sudafricano llevó a cabo una serie de reformas legislativas con el objetivo principal de tomar medias para dejar atrás las políticas del apartheid. En dicho paquete de reformas incluyó la obligación de todas las empresas mineras de cumplir con dos requisitos: I) en una plazo de 10 años, el control del $26 \%$ de sus acciones deberían estar en manos de sudafricanos «históricamente en desventaja» y II) el deber de publicar planes de empleo equitativo dirigidos a la inclusión en las plantillas de un $40 \%$ de personas negras ${ }^{45}$. La respuesta de empresas italianas y luxemburguesas fue denunciar a Sudáfrica, aprovechando los TBI entre sus países de origen y este último, alegando que las medidas tomadas por el Gobierno sudafricano debían considerarse una expropiación indirecta, ya que modificaban ampliamente sus derechos, por lo que reclamaban una indemnización de 375 millones de dólares ${ }^{46}$. El Gobierno sudafricano argumentó que la supuesta expropiación estaría amparada en el Derecho Interno, ya que estaría justificada por diversos motivos, entre ellos la reparación de la privación de derechos provocada por el apartheid ${ }^{47}$. El proceso se resolvió mediante acuerdo de las

${ }^{42}$ UNCTAD, 2018, op. cit., p. 36.

43 Bohoslavsky, J.P. y Justo, J.B., op. cit., p. 73.

${ }^{44}$ UNCTAD, 2018, op. cit., p.37.

45 Caso Ciadi No ARB(AF)/07/1. Párrafo 56.

46 Según datos de la UNCTAD. Disponible en https://investmentpolicy.unctad.org/investment-dispute-settlement/cases/262/foresti-v-south-africa.

${ }^{47}$ Bas Vilizzio, M. y Michelini, F., 2019, op. cit., p. 28. 
partes, por lo que el laudo de 4 de agosto de 2010 no entró a analizar las cuestiones de fondo. Pese a ello la reacción de Sudáfrica fue inmediata, ya que el mismo año comenzó a tomar medidas para modificar su política respecto a los TBI. El Gobierno decidió no obligarse mediante nuevos acuerdos de inversión y revisó todos los TBI en vigor con vistas a su terminación ${ }^{48}$. En el año 2015 Sudáfrica dio por finalizados todos sus TBI con países europeos y desarrolló una nueva Ley de Protección de Inversiones, que presentó como principal novedad el abandono del sistema de solución de controversias del CIADI, sustituyéndose por una instancia doméstica ${ }^{49}$.

El caso expuesto sirve de ejemplo del riesgo que supone este tipo de cláusulas. En base a éstas, las empresas pueden estar legitimadas para denunciar medidas tomadas por el Estado en materia de derechos humanos, por «modificar ampliamente sus derechos» en contra de sus intereses.

\subsection{El SISTEMA DE SOlUCiÓN DE CONTROVERSIAS INVERSO-ESTADO (ISDS)}

La mayoría de TBI establece un sistema de solución de las controversias con un mecanismo inversor-Estado, mediante el cual las empresas nacionales de una de las dos partes que tengan inversión en el territorio de la otra parte podrán demandar directamente al Estado receptor de la inversión. Algunos tratados optan por resolver la disputa en los tribunales nacionales del Estado receptor, pero la mayoría alude a la fórmula del tribunal internacional de arbitraje. Existen varias instituciones a las que suelen acudir los Estados, entre las que destaca el Centro Internacional de Arreglo de Diferencias Relativas a Inversiones (CIADI), que forma parte del Grupo del Banco Mundial ${ }^{50}$. Otras instancias similares son la Corte Permanente de Arbitraje de La Haya, la Cámara de Comercio de Estocolmo o la Cámara Internacional de Comercio.

48 Carim, X., «International Investment Agreements and Africa's Structural Transformation: A Perspective from South Africa», Investment Policy Brief, núm. 4, South Centre, 2015 , p. 4. Disponible en https://www.southcentre.int/wp-content/uploads/2015/08/IPB4_IIAs-and-Africa\%E2\%80\%99s-Structural-Transformation-Perspective-from-South-Africa_EN.pdf.

49 Qumba, M.F., "South Africa's move away from international investor-state dispute: a breakthrough or bad omen for investment in the developing world?», De Jure Law Journal, 2019, p. 359. Disponible en https://www.researchgate.net/publication/337011094_South_Africa's_move_ away_from_international_Investor-State_arbitration.

50 Según su propia página web, «una de las fuentes más importantes de financiamiento y conocimiento para los países en desarrollo, está integrado por cinco instituciones que se han comprometido a reducir la pobreza, aumentar la prosperidad compartida y promover el desarrollo sostenible». Aparte del CIADI, está conformado por el Banco Internacional de Reconstrucción y Fomento, la Asociación Internacional de Fomento, la Corporación Financiera Internacional y el Organismo Multilateral de Garantía de Inversiones. Información disponible en https://www.bancomundial.org. 
La importancia de los tribunales de arbitraje es enorme y se han ocupado de un gran número de $\operatorname{casos}^{51}$. La primera demanda de un país latinoamericano tuvo como destinatario a Venezuela en el año 1996. Los países de América del Sur, América Central y el Caribe han sido demandados en 282 ocasiones, 206 de las cuales se reparten entre Argentina (62), Venezuela (52), México (33), Ecuador (25), Bolivia (17) y Perú $(17)^{52}$. De los 282 casos, en 179 hubo una resolución (por laudo de arbitraje o por acuerdo de las partes), resultando beneficiado el inversor en el 69\% de los casos. En cuanto a las consecuencias económicas, los tribunales de arbitraje han dictaminado el pago por parte de los Estados lationamericanos de un total de 31170 millones de dólares ${ }^{53}$.

La principal crítica que se le hace al sistema ISDS es la falta de transparencia de los tribunales, ya que normalmente los laudos sólo se hacen públicos si hay acuerdo entre las partes ${ }^{54}$. Otra de las principales críticas es la gran incertidumbre jurídica que provocan. Incluso los procedimientos con normas establecidas, como el CIADI, constituyen un tribunal ad hoc para cada caso que no tiene obligación de respetar los precedentes ${ }^{55}$. Así mismo, los sistemas de apelación son casi inexistentes. Ambas circunstancias provocan una gran inseguridad jurídica para todas las partes.

Los árbitros suelen ser elegidos entre un reducido número de profesionales de reconocido prestigio en el ámbito del derecho mercantil internacional, lo que suele dar lugar a que individuos compaginen sus laborales arbitrales en un caso con el asesoramiento a las partes en otros ${ }^{56}$. El gran conocimiento en derecho mercantil internacional es una ventaja para entrar a conocer el fondo de la disputa, pero puede ser un inconveniente a la hora de aplicar otras normas de derecho internacional, como las concernientes a los derechos humanos ${ }^{57}$. También destacan sus elevados honorarios, tres mil dólares por árbitro y día de sesión.

Como se ha expuesto, los tratados de vieja generación han supuesto y suponen una clara limitación a la capacidad regulatoria de los Estados en materia de derechos humanos. En el momento de negociar estos tratados los Estados desconocían en gran medida las consecuencias jurídicas y económicas que iban a tener dichos acuerdos, así como las conflictivas interpretaciones que iban a realizar los árbitros internacionales de muchas de las cláusulas ambiguas ${ }^{58}$. Pero en la actua-

51 Durante el año 2019 se alcanzó la simbólica cifra de 1000 disputas inversor-Estado. Datos disponibles en el buscador de disputas inversor-Estado de la UNCTAD https://investmentpolicy.unctad.org/investment-dispute-settlement.

52 Transnational Institute, ISDS en números: impactos de las demandas de arbitraje de inversores contra estados de América Latina y el Caribe, Transnational Institute Amsterdam, 2020. Disponible en https://www.tni.org/es/publicacion/isds-en-numeros.

${ }^{53}$ La cantidad total es mayor, pero hay muchos laudos que no se publican.

${ }^{54}$ UNCTAD, 2018, op. cit., p. 30.

55 JАСОВ, M., op. cit., p. 24.

56 ЈАСОВ, M., op. cit., p. 25.

57 JасОв, M., op. cit., p. 25.

58 En este sentido es muy clarificador el estudio realizado por Poulsen y Skovgard, en el que entrevistaron a treinta funcionarios que durante la década de los noventa fueron parte de nego- 
lidad ya no puede esgrimirse dicho argumento. Los Estados que negocian nuevos acuerdos de inversión son plenamente conscientes del potencial conflictivo de cada una de las disposiciones. A continuación se analizan tres ejemplos de posible acción estatal al respecto.

\section{TRES OPCIONES DE ACCIÓN ESTATAL ANTE LOS TBI DE VIEJA GENERACIÓN}

Una vez analizados los principales puntos de fricción entre TBI y obligaciones en materia de derechos humanos expondremos tres alternativas de acción estatal a través del ejemplo de tres países latinoamericanos que reflejan diferentes formas de afrontar el problema: mantenerse fiel al sistema tradicional de protección de las inversiones (México), impugnar el sistema y abandonarlo unilateralmente (Ecuador) y generar posibles alternativas más compatibles con los derechos humanos (Brasil).

\subsection{El CASO MEXICANO O QUE TODO SIGA IGUAL}

En la actualidad México forma parte de 29 TBI en vigor, así como de once tratados de libre comercio (TLC) que establecen un mecanismo de solución de controversias inversor-Estado. Las demandas resultantes de estos acuerdos lo convierten en el sexto país más demandado de América Latina ante tribunales de arbitraje, y ha sido condenado a pagar un total 254 millones de dólares a distintos inversores. A día de hoy tiene 13 casos pendientes en los que los inversores exigen un total de 8300 millones de dólares ${ }^{59}$.

México es el claro ejemplo de Estados que han decidido mantener una política de inversiones continuista y que no han abandonado la defectuosa «vieja generación» de TBI. En la actualidad, 19 de los 29 citados TBI ya han alcanzado la fase en la que el Gobierno mexicano podría optar unilateralmente por denunciarlos y comenzar así las negociaciones de nuevos acuerdos revisados en los que poder incluir nuevas disposiciones. Sin embargo, nada parece indicar que éste vaya a ser el camino a tomar. Más bien todo lo contrario, ya que en el año 2018 México entró a formar parte de la Convención del CIADI, convirtiéndose en el Estado parte 154.

ciaciones de TBI en representación de otros tantos países. En el mismo, afirman que ninguno de los funcionarios era consciente, en el momento de la negociación, de las importantísimas consecuencias que les esperaban a sus países y que hasta las primeras demandas recibidas y las primeras interpretaciones arbitrales no tenían una imagen real de los problemas jurídicos a los que estaban expuestos. Skovgaard Poulsen, L.N. y Aisbett, E., «When the claim hits: bilateral investment treaties and bounded rational learning», World Politics, vol. 65, núm. 2, 2013, pp. 273-313. Disponible en http:// eprints.lse.ac.uk/45035/1/When\%20the\%20Claim\%20Hits\%20(LSERO).pdf.

${ }^{59}$ Datos recopilados por el Transnational Institute, disponibles en https://isds-americalatina.org/mexico/. 
Este compromiso afianza los lazos del Estado mexicano con el régimen de protección de las inversiones y con los mecanismos de ISDS.

Así mismo, y pese a ser consciente, por haberlas sufrido de forma directa, de las posibles consecuencias de muchas disposiciones de los tratados de vieja generación, el Gobierno mexicano ha firmado recientemente varios acuerdos en los que mantiene exactamente las mismas cláusulas de los TBI de la década de los noventa: nación más favorecida, trato justo y equitativo, expropiación indirecta y resolución de controversias inversor-Estado ante un tribunal de arbitraje internacional, entre otras. Es el caso de los convenios firmados con Bahréin ${ }^{60}$ (con entrada en vigor en 2014), Kuwait ${ }^{61}$ (2016) o Emiratos Árabes Unidos ${ }^{62}$ (2018). En la misma línea cabe destacar que el 1 de julio de 2020 entró en vigor el Tratado de Libre Comercio entre México, Estados Unidos y Canadá (T-MEC ${ }^{63}$ ), que, pese a no ser un TBI, contiene un importante capítulo de inversiones ${ }^{64}$ que incluye todas las cláusulas cuyos riesgos han sido analizados en este trabajo, así como un sistema ISDS.

La postura mexicana continuista resalta aún más si se tiene en cuenta el acuerdo firmado con Brasil ${ }^{65}$ en el año 2015, que se adapta al modelo brasileño que analizaremos más adelante y cuyo contenido se distancia radicalmente de los «nuevos convenios de vieja generación» firmados por México en los últimos años. Es muy reseñable que pese a conocer los riesgos de los TBI más tradicionales y pese a firmar un acuerdo con Brasil con todas las características de la nueva generación, México se siga comprometiendo a nivel internacional mediante tratados que pueden significar una importante limitación para su capacidad de cumplir sus obligaciones en materia de derechos humanos.

\subsection{El CASO DE ECUAdOR: IRSE ¿PARA SIEMPRE?}

Ecuador representa una postura muy distante de la opción mexicana ya que, pese a mantener durante muchos años una relación de cordialidad con el sistema de ISDS, decidió dar un giro importante. En enero de 2008, menos de un año después de la llegada a la presidencia de Rafael Correa, Ecuador notificó la denuncia de nueve de los $26 \mathrm{TBI}$ en vigor de los que formaba parte ${ }^{66}$, los únicos que no habían gene-

${ }^{60}$ Disponible en https://investmentpolicy.unctad.org/international-investment-agreements/ treaties/bilateral-investment-treaties/3599/bahrain---mexico-bit-2012-.

${ }^{61}$ Disponible en https://investmentpolicy.unctad.org/international-investment-agreements/ treaties/bilateral-investment-treaties/3426/kuwait---mexico-bit-2013-.

${ }^{62}$ Disponible en https://investmentpolicy.unctad.org/international-investment-agreements/ treaties/bilateral-investment-treaties/3682/mexico---united-arab-emirates-bit-2016-.

${ }_{63}$ Texto completo disponible en https://www.gob.mx/t-mec.

${ }^{64}$ Capítulo 14 del T-MEC.

${ }_{65}$ Disponible en https://investmentpolicy.unctad.org/international-investment-agreements/ treaties/bilateral-investment-treaties/3665/brazil---mexico-bit-2015-.

${ }^{66}$ Cuba, El Salvador, Guatemala, Honduras, Nicaragua, Paraguay, República Dominicana, Rumanía y Uruguay. 
rado ninguna inversión ${ }^{67}$. En octubre del mismo año entró en vigor la nueva Constitución ecuatoriana, que en su artículo 422 hace referencia al arbitraje internacional:

«No se podrá celebrar tratados o instrumentos internacionales en los que el Estado ecuatoriano ceda jurisdicción soberana a instancias de arbitraje internacional, en controversias contractuales o de índole comercial, entre el Estado y personas naturales o jurídicas privadas ${ }^{68}$.

Utilizando dicho artículo como argumento, en julio de 2009, Ecuador denunció y dio por terminado el Convenio CIADI. Así mismo, el Gobierno solicitó una sentencia de la Corte Constitucional Transitoria en torno a la constitucionalidad de los 17 TBI restantes, que resolvió que dichos acuerdos contravenían la prohibición de ceder jurisdicción soberana del artículo $422^{69}$. En 2013, Correa impulsó la creación de la Comisión para la Auditoría Integral Ciudadana de los Tratados de Protección Recíproca de Inversiones y del Sistema de Arbitraje Internacional en Materia de Inversiones (CAITISA), la cual concluyó en su informe del 8 de mayo de 2017 que los TBI no contribuían a atraer inversión extranjera, recomendando su terminación ${ }^{70}$. Tan sólo unos días después, el 16 de mayo de $2017^{71}$, el Gobierno formalizó la salida de Ecuador de los 16 TBI restantes ${ }^{72}$.

Con la llegada de Lenin Moreno al poder, se percibe un posible cambio de rumbo, ya que el nuevo Gobierno anunció la intención de negociar nuevos tratados bilaterales de inversión ${ }^{73}$ y en 2019 celebró con Brasil un CFIA ${ }^{74}$, con un sistema de solución de controversias Estado-Estado, dejando de lado por primera vez el mecanismo inversor-Estado. Al ser consultada al respecto, la Corte Constitucional señaló que

${ }^{67}$ Bas Vilizzio, M., «Algunas reflexiones en torno al retiro de Bolivia, Ecuador y Venezuela del CIADI», Densidades, núm. 17, 2015, pp. 51-67. Disponible en https://www.researchgate. net/publication/285386774_Algunas_reflexiones_en_torno_al_retiro_de_Bolivia_Ecuador_y_ Venezuela_del_CIADI.

${ }^{68}$ Artículo 422 de la Constitución de la República del Ecuador del 20 de noviembre de 2008. Disponible en https://www.oas.org/juridico/pdfs/mesicic4_ecu_const.pdf.

${ }^{69}$ Véase como ejemplo la sentencia de la Corte Constitucional Transitoria N. ${ }^{\circ} 043-10-D T I-C C$, de 25 de noviembre de 2010, sobre la constitucionalidad del «Tratado entre la República del Ecuador y los Estados Unidos de América sobre promoción y protección recíproca de inversiones», de 1993. Disponible en http://portal.corteconstitucional.gob.ec:8494/FichaRelatoria.aspx?numdocumento $=043-10-$ DTI-CC.

${ }^{70}$ Herrera-Quenguan, J.C., «Explicando el Cambio de Postura de Ecuador sobre la IED, los Tratados y el Arbitraje de Inversión", Investment Treaty News, Instituto Internacional para el Desarrollo Sostenible, 2020. Disponible en https://cf.iisd.net/itn/es/2020/10/05/explaining-ecuadors-shifting-position-on-fdi-investment-treaties-and-arbitration-juan-carlos-herrera-quenguan/.

${ }^{71}$ Correa recibió numerosas críticas, ya que formalizó la salida de los TBI tan sólo ocho días de antes de abandonar la presidencia del Gobierno.

${ }^{72}$ Alemania, Argentina, Bolivia, Canadá, Chile, China, España, Estados Unidos, Francia, Italia, Países Bajos, Perú, Reino Unido, Suecia, Suiza y Venezuela. En el año 2010 se denunció el TBI con Finlandia.

${ }^{73}$ https://globalarbitrationreview.com/article/1159285/ecuador-begins-talks-over-new-bits.

${ }_{74} \overline{\text { Disponible en https://investmentpolicy.unctad.org/international-investment-agreements/ }}$ treaty-files/5887/download. 
los mecanismos de solución de disputas previstos en el Acuerdo, entre los cuales se encuentra el arbitraje, están exclusivamente destinados a solventar las disputas que puedan surgir entre las Partes, esto es, entre Estados. Esta resolución de disputas no es una competencia propia del orden jurídico interno de un Estado, por lo que al pactar arbitraje en el presente Acuerdo, no se está atribuyendo una competencia de esta naturaleza a un organismo internacional o supranacional ${ }^{75}$.

A la espera de los resultados de las negociaciones de los nuevos tratados, Ecuador sigue siendo uno de los mejores ejemplos de ruptura con el sistema de protección de inversiones. Esta impugnación del sistema tuvo un marcado carácter ideológico e importantes motivaciones partidistas, por lo que existen serias dudas sobre si dicha postura se mantendrá en el tiempo.

\subsection{Brasil: los CFIA como alternativa a los TBI de Vieja Generación}

Brasil es uno de los casos más interesantes en relación con el sistema de protección de inversiones, ya que puede considerarse el único país del mundo con un peso económico relevante que nunca ha firmado un TBI y que se ha mantenido ajeno al sistema ISDS $^{76}$. Pese a ello, Brasil ha sido tradicionalmente uno de los Estados con mayor captación de IED, situándose en la quinta posición mundial durante el año $2019^{77}$.

Entre 1994 y 1999 Brasil firmó catorce acuerdos, pero ninguno de ellos fue aprobado por el Congreso brasileño. Los argumentos utilizados fueron los períodos de tiempo demasiado extensos por los que se comprometía al Estado, la discriminación que significaría privilegiar a los inversores extranjeros frente a los nacionales y los posibles problemas de constitucionalidad en relación con la solución de controversias mediante el arbitraje inversor-Estado ${ }^{78}$. En el año 2002 se creó un Grupo de Trabajo Interministerial que decidió retirar dichos acuerdos del Congreso ${ }^{79}$.

Pese a no haber ratificado ningún TBI, Brasil no ha dejado de lado la regulación de la IED, pero ha buscado una alternativa que subsane los defectos del sistema de protección tradicional. A partir de 2015, Brasil comenzó a firmar un nuevo

75 Sentencia N. ${ }^{\circ}$ 34-19-TI/19, de 27 de junio de 2020, de la Corte Constitucional de Ecuador. Disponible en http://portal.corteconstitucional.gob.ec:8494/BuscadorRelatoria.aspx.

76 Aстіs, E., «Brasil y la promoción de Tratados Bilaterales de Inversión: El fin de la disyuntiva», Latin American Journal of International Affairs, vol. 6, núm. 1, 2014, pp. 18-33.

77 Datos de la Comisión Económica para América Latina y el Caribe de Naciones Unidas (CEPAL). Disponible en https://www.cepal.org/es/publicaciones/ie.

${ }^{78}$ Bas Vilizio, M., «Solución de controversias en los tratados bilaterales de inversión: mapa de situación en América del sur", Revista de la Secretaría del Tribunal Permanente de Revisión, núm. 5 (3), 2015, pp. 233-253. Disponible en https://redib.org/Record/oai_articulo935776-soluci $\% \mathrm{C} 3 \% \mathrm{~B} 3 n$-de-controversias-en-los-tratados-bilaterales-de-inversi $\% \mathrm{C} 3 \% \mathrm{~B} 3 \mathrm{n}$-mapa-de-situaci\%C3\%B3n-en-am\%C3\%A9rica-del-sur.

${ }^{79}$ ACTIS, E., op. cit., p. 23. 
tipo de tratado a los que denomina Acuerdos de Cooperación y Facilitación de Inversiones (CFIA por sus siglas en inglés). Estos documentos rompen de manera clara con el modelo tradicional de los TBI. El CFIA entre Brasil y la India ${ }^{80}$, firmado el 25 de enero de $2020^{81}$, es un claro ejemplo del nuevo rumbo que pueden tomar los TBI para enmendar las deficiencias de la vieja generación y generar un sistema de protección de inversiones que no colisione con las obligaciones en materia de derechos humanos.

Dicho acuerdo destaca, en primer lugar, por renunciar a la inclusión de las cláusulas más conflictivas de los TBI tradicionales y por aumentar la concreción de las disposiciones que sí se mantienen. Por ejemplo, el texto no hace ninguna referencia al estándar de trato justo y equitativo ${ }^{82}$, ni a la cláusula de nación más favorecida, y de forma expresa sólo incluye la expropiación directa, que sólo ocurre cuando «an investment is nationalised or otherwise directly expropiated through formal transfer tittle or outright seizure ${ }^{83}{ }_{\text {». }}$. Respecto a la cláusula de trato nacional, especifica que será otorgado en "circunstancias similares» ${ }^{84}$ y ańade, para mayor certeza, que las circunstancias similares dependen de la totalidad de las mismas y en ningún caso se podrá interpretar obligando a las partes a compensar desventajas intrínsecas que resulten del carácter extranjero del inversor ${ }^{85}$. De esta forma, el convenio se deshace de toda posible disposición que pueda significar un perjuicio importante para la capacidad regulatoria de ambas partes. En este sentido, el artículo 4.2 añade que ningún elemento del tratado podrá ser interpretado en un sentido que impida a una parte la adopción o mantenimiento de medidas de acción afirmativas a favor de grupos vulnerables.

En lo que respecta a los mecanismos de solución de controversias, en línea con la posición tradicional de Brasil al respecto, el acuerdo renuncia a la posibilidad de un arbitraje inversor-Estado. En cambio, opta por incluir un procedimiento de prevención de las disputas ${ }^{86}$, al que los Estados parte podrán acudir si consideran que la otra parte ha llevado a cabo una conducta que pueda ir en contra de lo estipulado en el tratado. La parte interesada deberá presentar un informe con sus alegaciones al Joint Comittee, órgano encargado de la administración del tratado formado por representantes gubernamentales de ambas partes ${ }^{87}$, que tomará una decisión al respecto. En el caso en el que la disputa esté relacionada con un único inversor, los

${ }^{80}$ Disponible en https://investmentpolicy.unctad.org/international-investment-agreements/ treaties/bilateral-investment-treaties/4910/brazil---india-bit-2020-.

${ }^{81}$ Aún no ha entrado en vigor.

${ }^{82}$ Dietrich Brauch, M., «¿Lo Mejor de Dos Mundos? El Tratado de Cooperación y Facilitación de Inversiones entre Brasil e India», Investment Treaty News. 2020. Disponible en https:// www.iisd.org/itn/es/2020/03/10/the-best-of-two-worlds-the-brazil-india-investment-cooperationand-facilitation-treaty-martin-dietrich-brauch/.

${ }^{83}$ Artículo 6.3.

${ }_{84}$ Artículo 5.1.

${ }^{85}$ Artículo 5.3.

${ }^{86}$ Artículo 18.

${ }^{87}$ Regulado en el artículo 13. 
representantes de éste serán escuchados durante el proceso, pero en ningún caso tendrán la opción de iniciar el mismo. Si se da la circunstancia de que las partes no quedan satisfechas con el procedimiento de prevención de disputas, existe la opción de establecer un tribunal arbitral $a d$ hoc entre las propias partes, o, siempre mediante acuerdo mutuo, acudir a una institución permanente de arbitraje. En ningún caso el tribunal de arbitraje podrá estipular una compensación económica ${ }^{88}$ y el procedimiento sólo podrá ser iniciado por uno de los dos Estados, nunca por un inversor.

Otro de los aspectos más destacables del acuerdo es que, al igual que todos los CFIA participados por Brasil, incluye un apartado de obligaciones y responsabilidades de los inversores, e incluso establece disposiciones respecto a la Responsabilidad Social Corporativa (RSC) de éstos. El tratado establece que tanto los inversores como las inversiones deben desarrollar sus mejores esfuerzos para conseguir «the highest possible level of contribution to the sustainable development of the Host State and the local community ${ }^{89}{ }$. A sí mismo, determina que los inversores deberán esforzarse en acatar una serie de principios voluntarios y estándares de RSC, entre los que destacan los derechos humanos reconocidos internacionalmente de aquéllos involucrados en las actividades de las compañías.

Pese a lo innovador y alejado de las prácticas de la vieja generación de esta última medida, defendemos que estos acuerdos aún podrían ser más ambiciosos y sustituir los términos como "deberán esforzarse» o "deberán poner todo su empeño» por un lenguaje que establezca de forma más clara la obligación de cumplir, como sí hace en los artículos relacionados con las obligaciones en materia de impuestos o adquisiciones ${ }^{90}$. Así mismo, consideramos que la exclusión del capítulo de obligaciones y responsabilidades de los inversores de las materias susceptibles de ser sometidas a arbitraje entre las partes es una oportunidad perdida. La hipotética situación en la que un Estado pueda llegar a iniciar un procedimiento de arbitraje contra la otra parte sobre la base de que una empresa de esta nacionalidad no está esforzándose lo suficiente por respetar los derechos humanos en su territorio abre todo un panorama de interesantes posibilidades.

Pese a estos últimos aspectos, el camino tomado por Brasil dibuja de forma clara un posible escenario en el que el fomento de la inversión extranjera no colisione con las obligaciones internacionales de los Estados en materia de derechos humanos.

\section{CONCLUSIONES}

Los TBI de «vieja generación» contienen cláusulas y mecanismos de resolución que pueden llegar a limitar de forma sustancial la capacidad regulatoria de los Estados receptores en materias relacionadas con las inversiones extranjeras. Los

\footnotetext{
${ }^{88}$ Artículo 19.2

${ }^{89}$ Artículo 12.1.

90 Artículo 11.
} 
intereses de los inversores son tan amplios y tan interrelacionados con los derechos humanos que la limitación de la posibilidad de los Estados de llevar a cabo medidas legislativas que los puedan afectar de forma negativa supone un claro riesgo de entorpecer la capacidad de los países de cumplir sus obligaciones en materia de derechos humanos.

Ante tal escenario, resulta necesaria una revisión profunda de los acuerdos que fomentan la inversión que permita hacerlos compatibles con la protección de los derechos humanos. Por ello, los Estados deben aprovechar el momento actual y, siguiendo el modelo brasileńo, negociar nuevos convenios que establezcan cláusulas menos conflictivas y mejor definidas, que incorporen obligaciones para los inversores y que abandonen el modelo de solución de controversias inversor-Estado que tantos quebraderos de cabeza ha generado. De lo contrario, los Estados que sigan comprometiéndose ante nuevos TBI que incluyan las antiguas cláusulas, cuyas consecuencias negativas son ya conocidas, estarán tomando la decisión, voluntaria y consciente, de limitar en gran medida su capacidad de cumplir sus obligaciones internacionales en materia de derechos humanos.

ReCibido: septiembre de 2020; ACEPTADo: diciembre de 2020 
